Article

\title{
Recovery of Wheat Heritage for Traditional Food: Genetic Variation for High Molecular Weight Glutenin Subunits in Neglected/Underutilized Wheat
}

\author{
Juan B. Alvarez *(i) and Carlos Guzmán (1) \\ Departamento de Genética, Escuela Técnica Superior de Ingeniería Agronómica y de Montes, \\ Edificio Gregor Mendel, Campus de Rabanales, Universidad de Córdoba, CeiA3, ES-14071 Córdoba, Spain; \\ carlos.guzman@uco.es \\ * Correspondence: jb.alvarez@uco.es
}

Received: 2 October 2019; Accepted: 13 November 2019; Published: 14 November 2019

check for updates

\begin{abstract}
Club wheat (Triticum aestivum L. ssp. compactum (Host) Mackey), macha wheat (T. aestivum L. ssp. macha (Dekapr. \& A.M. Menabde) Mackey) and Indian dwarf wheat (T. aestivum L. ssp. sphaerococcum (Percival) Mackey) are three neglected or underutilized subspecies of hexaploid wheat. These materials were and are used to elaborate modern and traditional products, and they could be useful in the revival of traditional foods. Gluten proteins are the main grain components defining end-use quality. The high molecular weight glutenin subunit compositions of 55 accessions of club wheat, 29 accessions of macha wheat, and 26 accessions of Indian dwarf wheat were analyzed using SDS-PAGE. Three alleles for the Glu-A1 locus, 15 for Glu-B1 (four not previously described), and four for Glu-D1 were detected. Their polymorphisms could be a source of genes for quality improvement in common wheat, which would permit both their recovery as new crops and development of modern cultivars with similar quality characteristics but better agronomic traits.
\end{abstract}

Keywords: electrophoresis; genetic resources; neglected hexaploid wheat; seed-storage proteins

\section{Introduction}

Wheat is an important crop that has been associated with human food for many centuries [1]. It is the basis for a diverse range of products, mainly bread, noodles, pasta, and beer, which are present in most diets worldwide. In some cases, the same wheat type is used for all four different products depending on the geographical or cultural area [2]. Up until the Industrial Revolution, all baking processes were carried out by hand, which permitted the use of wheat varieties with rheological properties greatly different to current wheat varieties. Nevertheless, the use of machinery in baking processes forced people to look for varieties with very specific qualities [3], neglecting the traditional wheats mainly because of their lower yields and, in many cases, their unsuitability for mechanized production.

In recent times, in many places throughout the world, the search for more balanced and healthier diets has strengthened the return to traditional products [4]. However, paradoxically, one of the main problems is the need to use the flour of modern cultivars to develop these old products, and this is not successful in all cases because the modern cultivars have characteristics adapted to new uses. In this context, recovery of the materials that were traditionally used to develop these products has proven to be key in this revival.

In addition, some studies have suggested that the wheat breeding programs centered on high-yield cultivars could have eroded the genetic variability from the quality traits among and within cultivars [5]. This has given great importance to the search for species that could be useful in contributing genes 
for wheat quality improvement [6]. Wheat relatives are considered to be interesting sources of new alleles for these traits that could increase the crop's genetic basis [7]. Among these relatives, the wild relatives as well as the old varieties and landraces of the current or ancient wheats of all ploidic levels are included. Utilization of these latter materials as gene sources is advantageous, compared to the wild relatives, because they are easy to cross with modern wheat and there is little linkage drag of unwanted traits, which results from their high degree of domestication [8].

Wheat quality is associated with three main grain components: endosperm storage proteins related to gluten visco-elastic properties [9], starch synthases related to starch [10], and puroindolines related to grain hardness [11]. The endosperm storage proteins are divided in two main groups, gliadins and glutenins, according to their molecular characteristics [12]. Glutenins are also divided into high molecular weight (HMWGs) and low molecular weight (LMWGs) subunits [13,14]. HMWGs are coded at the Glu-1 loci located on the long arm of group-1 homologous chromosomes, whereas the Glu-3 loci that code for the LMWGs and the Gli-1 loci that controls synthesis of $\omega_{--}, \gamma_{-}^{-}$, and some $\beta$-gliadins are located on the short arm. On the short arm of group- 6 homologous chromosomes, the Gli-2 loci that code mainly for components present in the $\alpha$ region and some $\beta$-gliadins are located [15]. Among the endosperm storage proteins, the best studied are the HMWG subunits coded at the Glu-A1, Glu-B1, and Glu-D1 loci on the long arm of group-1 homologous chromosomes in common wheat [12]. Each locus consists of two linked genes that code for two types of HMWG subunits, with different mobilities in SDS-PAGE, named $x$ - and $y$-types [16].

Within the hexaploid species, over the last decade, our research group has conducted several studies on the genetic diversity for endosperm storage proteins, waxy proteins, and puroindolines in Spanish and Mexican landraces of common wheat (Triticum aestivum L. ssp. aestivum) $[17,18]$ and Spanish spelt wheat (T. aestivum L. ssp. spelta (L.) Thell.) [19-22]. Recently, other neglected or underutilized wheat subspecies have been screened for genes related to quality traits, including club wheat (T. aestivum L. ssp. compactum (Host) Mackey) (important in the Pacific Northwest region in the USA but not in the rest of the world) and Indian dwarf wheat (T. aestivum L. ssp. sphaerococcum (Percival) Mackey), both included within the naked wheat group as common wheat, and macha wheat (T. aestivum L. ssp. macha (Dekapr. \& A.M. Menabde) Mackey) from the same hulled wheat group as spelt wheat. Our data obtained with these species showed notable variability for waxy proteins (granule-bound starch synthase I, E.C. 2.4.11.11), detecting new allelic variants for starch synthase not previously described in common wheat [23]. However, variability studies on the endosperm storage proteins in these species have been scarce, showing low variation [24,25].

The main goal of this survey was to evaluate the polymorphisms of the seed storage proteins present in a collection of hexaploid wheats, club wheat, macha wheat, and Indian dwarf wheat, collected in their natural distribution areas. The variation of these wheats for endosperm storage proteins could be a good source of quality genes for common wheat breeding, increasing the wheat genetic background together with the development of new cultivars.

\section{Materials and Methods}

\subsection{Plant Material}

Fifty-five accessions of club wheat, 29 accessions of macha wheat, and 26 accessions of Indian dwarf wheat obtained from the National Small Grain Collections (Aberdeen, ID, USA) were analyzed in this study (Tables S1, S2 and S3). At least five grains for each accession were analyzed to detect the possible intra-accession variability.

The HMWGs alleles were designated according to Payne and Lawrence [26]. Several cultivars of durum (cv. Lobeiro: 1, $14+15$ ) and common wheat (cv. Chinese Spring: null, $7+8,2+12$, cv. Cheyenne: $2^{*}, 7+9,5+10$, and cv. Frondoso: $2^{*}, 13+19,2+12$ ) were used as standards to compare and classify the detected subunits in the analyzed species. 


\subsection{Protein Extraction and SDS-PAGE Electrophoretic Analysis}

Proteins were extracted from crushed endosperm. Before glutenin solubilization, the gliadins were extracted with a $1.5 \mathrm{M}$ dimethylformamide aqueous solution following a double-wash with $50 \%$ (v/v) propan-1-ol at $60^{\circ} \mathrm{C}$ for $30 \mathrm{~min}$ with agitation every $10 \mathrm{~min}$. Glutenin was solubilized with $250 \mu \mathrm{L}$ of buffer containing 50\% (v/v) propan-1-ol, $80 \mathrm{mM}$ Tris- $\mathrm{HCl}(\mathrm{pH} 8.5)$, and $2 \%(\mathrm{w} / \mathrm{v})$ dithiothreitol at $60{ }^{\circ} \mathrm{C}$ for $30 \mathrm{~min}$. After centrifugation, $200 \mu \mathrm{L}$ of the supernatant was transferred to a new tube, mixed with $3 \mu \mathrm{L}$ of 4 -vinylpyridine, and incubated for $30 \mathrm{~min}$ at $60^{\circ} \mathrm{C}$. The samples were precipitated with $1 \mathrm{ml}$ of cold-acetone. The dried pellet was solubilized in buffer containing $625 \mathrm{mM}$ Tris-HCl ( $\mathrm{pH} 6.8), 2 \%(\mathrm{w} / \mathrm{v})$ SDS, $10 \%(\mathrm{v} / \mathrm{v})$ glycerol, $0.02 \%(\mathrm{w} / \mathrm{v})$ bromophenol blue, and $2 \%(\mathrm{w} / \mathrm{v})$ dithiothreitol in a 1:5 ratio $(\mathrm{mg} / \mu \mathrm{L})$ to wholemeal.

Reduced and alkylated glutenin subunits were fractionated by electrophoresis in vertical SDS-PAGE slabs in a discontinuous Tris-HCl-SDS buffer system ( $\mathrm{pH}: 6.8 / 8.8$ ) at a polyacrylamide concentration of $8 \%(\mathrm{w} / \mathrm{v}, \mathrm{C}: 1.28 \%$ ). The Tris-HCl/glycine buffer system of Laemmli [27] was used. Electrophoresis was performed at a constant current of $30 \mathrm{~mA} / g e l$ at $18{ }^{\circ} \mathrm{C}$ for $45 \mathrm{~min}$ after the tracking dye migrated off the gel. Gels were stained overnight with $12 \%(\mathrm{w} / \mathrm{v})$ trichloroacetic acid solution containing 5\% (v/v) ethanol and 0.05\% (w/v) Coomassie Brilliant Blue R-250. De-staining was carried out with tap water.

\subsection{Statistical Analysis}

Allelic frequencies for the Glu-A1, Glu-B1, and Glu-D1 loci were calculated for each subspecies. The classification of Marshall and Brown [28] was used for evaluating the distribution of alleles by their presence as frequent $(\geq 5 \%)$, rare $(\leq 5 \%)$, and very rare $(\leq 1 \%)$. To assess potential genetic erosion, the number of alleles per locus $(A)$, the effective number of alleles per locus (Ne), and Nei's diversity index $(\mathrm{He})$ were measured $[29,30]$.

\section{Results}

\subsection{Variation for $H M W G s$}

The HMWG compositions of all accessions of each subspecies (club, macha, and Indian dwarf wheat) were analyzed. A representative sample of the variability detected for the HMWGs in each subspecies is shown in Figure 1.

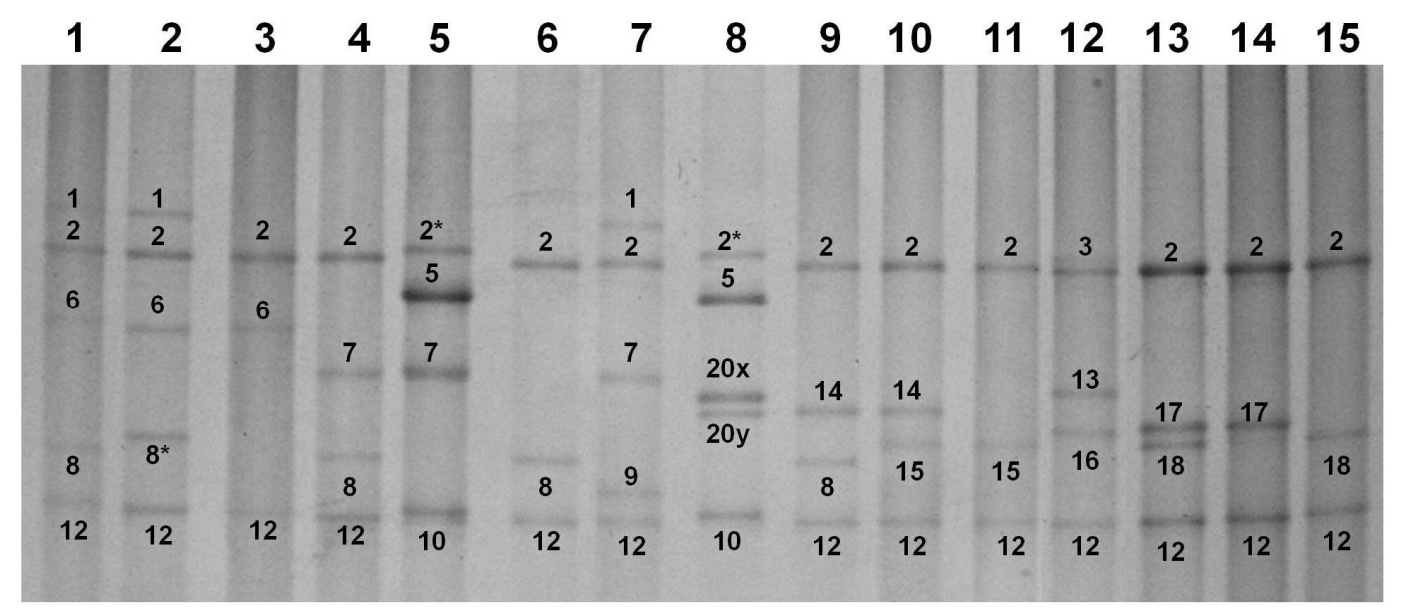

Figure 1. SDS-PAGE of representative variation for high molecular weight glutenin subunits (HMWGs) found in the collection of club (lanes 1,3,5-8, and 10-13), macha (lanes 2, 4, and 9), and Indian dwarf wheat (lanes 14 and 15). 
Twenty-one allelic variants ( 3 at the Glu-A1 locus, 15 at Glu-B1, and 3 at Glu-D1) were detected in the evaluated accessions (Table 1). Four out of the 15 for Glu-B1 locus were novel. The distribution of these alleles in each subspecies was unequal.

In club wheat, three alleles were found for the Glu-A1 locus, with the Glu-A1a allele being the least frequent (Table 1). The Glu-B1 locus was more variable with 11 alleles, although only 3 of them showed frequencies above the average value that should have occurred if the distribution was random (mean value $=9.1 \%$ ). The rest of the alleles were classified as rare according to the Marshall and Brown classification [28]. One of these rare alleles (null+15, Figure 1 lane 15) was also novel, detected only in accession PI 157920, and we propose to tentatively name this Glu-B1ck following the order of the Wheat Gene Catalogue [31]. For the Glu-D1 locus, one allele (Glu-D1a, subunits $2+12)$ was clearly hegemonic, being present in $78.2 \%$ of the accessions evaluated.

Table 1. Allelic frequency for Glu-A1, Glu-B1, and Glu-D1 loci of the evaluated accessions.

\begin{tabular}{|c|c|c|c|c|}
\hline \multirow[b]{2}{*}{ Allele } & \multirow[b]{2}{*}{ Subunit } & \multicolumn{3}{|c|}{ No. of Samples (Frequency (\%)) } \\
\hline & & $\begin{array}{l}\text { Club Wheat } \\
\quad(n=55)\end{array}$ & $\begin{array}{l}\text { Macha Wheat } \\
\quad(n=29)\end{array}$ & $\begin{array}{c}\text { Indian Dwarf Wheat } \\
(n=26)\end{array}$ \\
\hline \multicolumn{5}{|l|}{ Glu-A1 } \\
\hline$a$ & 1 & $8(14.5)$ & $5(17.2)$ & - \\
\hline$b$ & $2^{*}$ & $27(49.1)$ & $6(20.7)$ & $5(19.2)$ \\
\hline$c$ & null & $20(36.4)$ & $18(62.1)$ & $21(80.8)$ \\
\hline \multicolumn{5}{|l|}{ Glu-B1 } \\
\hline$a$ & $7+$ null & $3(5.5)$ & - & - \\
\hline$b$ & $7+8$ & $21(38.2)$ & $17(58.6)$ & $1(3.8)$ \\
\hline$c$ & $7+9$ & $4(7.3)$ & $5(17.2)$ & $4(15.4)$ \\
\hline$d$ & $6+8$ & $3(5.5)$ & - & - \\
\hline$e$ & $20 x+20 y$ & $12(21.8)$ & $2(6.9)$ & $4(15.4)$ \\
\hline$f$ & $13+16$ & $2(3.6)$ & - & - \\
\hline$h$ & $14+15$ & $1(1.8)$ & - & - \\
\hline$i$ & $17+18$ & $2(3.6)$ & $1(3.4)$ & $11(42.3)$ \\
\hline$a j$ & null + 8 & $1(1.8)$ & - & - \\
\hline$a m$ & null +18 & - & - & 3 (11.5) \\
\hline \multirow[t]{5}{*}{$a n$} & $6+$ null & $5(9.1)$ & - & - \\
\hline & null +15 & $1(1.8)$ & - & - \\
\hline & $14+8$ & - & $3(10.3)$ & - \\
\hline & $6+8^{*}$ & - & $1(3.4)$ & - \\
\hline & $17+$ null & - & - & $3(11.5)$ \\
\hline \multicolumn{5}{|l|}{ Glu-D1 } \\
\hline$a$ & $2+12$ & $43(78.2)$ & $19(65.5)$ & $26(100.0)$ \\
\hline$b$ & $3+12$ & $5(9.1)$ & $4(13.8)$ & - \\
\hline$d$ & $5+10$ & 7 (12.7) & $6(20.7)$ & - \\
\hline
\end{tabular}

Similar to club wheat, macha wheat presented three alleles for the Glu-A1 locus, although in this case, one (Glu-A1c) was three times more frequent that the other two (Table 1). For Glu-B1, more than half of the materials presented the Glu-B1b allele, whereas two were rare and found in only one accession. Therefore, two novel alleles were detected in this subspecies (subunits $14+8$ and $6+8^{*}$, Figure 1 lanes 9 and 2, respectively). The first allele (subunits $14+8$ ) was present in three accessions (PI 272554, PI 278660, and PI 290507), whereas the second $\left(6+8^{*}\right)$ was only found in accession PI 428177. We propose to tentatively name these alleles $\mathrm{Glu}-\mathrm{B} 1 \mathrm{cl}$ and $\mathrm{Glu}-\mathrm{B} 1 \mathrm{~cm}$, respectively, following the current order in the Wheat Gene Catalogue [31]. The variation for the Glu-D1 locus was largest for the three subspecies, showing three alleles, one hegemonic (subunits $2+12$ ) and the other two with similar frequencies.

The variation for the Glu-A1 locus was low in Indian dwarf wheat, with only two alleles found and one representing more of $80 \%$ of the material (Table 1). The Glu-B1 locus showed some variation 
(six alleles); one of them (subunit 17+null, Fig.1 lane 14) was novel, detected in three accessions (CItr 4531, PI 272581, and PI 282452) and we propose to name it Glu-B1cn. In contrast, the materials were homogenous at the Glu-D1 locus. In this subspecies, only the Glu-B1b allele (subunits $7+8$ ) can be considered rare.

When the three loci were evaluated together, the number of combinations was highly variable among the three subspecies analyzed (Table 2), with eight in Indian dwarf wheat and 26 in club wheat.

Table 2. Frequencies of the HMW glutenin subunit compositions found among accessions analyzed.

\begin{tabular}{|c|c|c|c|c|c|c|c|}
\hline \multicolumn{4}{|c|}{ Club Wheat } & \multicolumn{4}{|c|}{ Macha Wheat } \\
\hline Glu-A1 & Glu-B1 & Glu-D1 & $\mathbf{N}$ & Glu-A1 & Glu-B1 & Glu-D1 & $\mathbf{N}$ \\
\hline 1 & $20 x+20 y$ & $2+12$ & 2 & 1 & $6+8^{*}$ & $2+12$ & 1 \\
\hline 1 & $13+19$ & $3+12$ & 1 & 1 & $7+8$ & $2+12$ & 3 \\
\hline 1 & $6+8$ & $2+12$ & 2 & 1 & $7+9$ & $2+12$ & 1 \\
\hline 1 & $7+8$ & $5+10$ & 1 & $2^{*}$ & $14+8$ & null +12 & 1 \\
\hline 1 & $7+9$ & $2+12$ & 1 & $2^{*}$ & $7+8$ & null +12 & 4 \\
\hline 1 & $7+9$ & $5+10$ & 1 & $2^{*}$ & $7+9$ & null +12 & 1 \\
\hline $2^{*}$ & $6+$ null & $2+12$ & 1 & null & $20 x+20 y$ & $3+12$ & 1 \\
\hline $2^{*}$ & $7+$ null & $2+12$ & 2 & null & $20 x+20 y$ & $5+10$ & 1 \\
\hline $2^{*}$ & $7+$ null & $5+10$ & 1 & null & $17+18$ & $2+12$ & 1 \\
\hline $2^{*}$ & $20 x+20 y$ & $2+12$ & 7 & null & $14+8$ & $2+12$ & 1 \\
\hline $2^{*}$ & $20 x+20 y$ & $5+10$ & 2 & null & $14+8$ & $3+12$ & 1 \\
\hline $2^{*}$ & $13+19$ & $2+12$ & 1 & null & $7+8$ & $2+12$ & 5 \\
\hline $2^{*}$ & $14+15$ & $2+12$ & 1 & null & $7+8$ & $5+10$ & 5 \\
\hline $2^{*}$ & $7+8$ & $2+12$ & 9 & null & $7+9$ & $2+12$ & 1 \\
\hline $2^{*}$ & $7+8$ & $3+12$ & 2 & null & $7+9$ & $3+12$ & 2 \\
\hline $2^{*}$ & $7+9$ & $2+12$ & 1 & & & & \\
\hline null & $6+$ null & $2+12$ & 4 & \multicolumn{4}{|c|}{ Indian Dwarf Wheat } \\
\hline null & null +8 & $2+12$ & 1 & $G l u-A 1$ & Glu-B1 & Glu-D1 & $\mathbf{N}$ \\
\hline null & null + 15 & $2+12$ & 1 & $2^{*}$ & $17+$ null & $2+12$ & 3 \\
\hline null & $20 x+20 y$ & $3+12$ & 1 & $2^{*}$ & null + 18 & $2+12$ & 1 \\
\hline null & $17+18$ & $2+12$ & 2 & $2^{*}$ & $17+18$ & $2+12$ & 1 \\
\hline null & $6+8$ & $2+12$ & 1 & null & null + 18 & $2+12$ & 2 \\
\hline null & $7+8$ & $2+12$ & 6 & null & $20 x+20 y$ & $2+12$ & 4 \\
\hline null & $7+8$ & $3+12$ & 1 & null & $17+18$ & $2+12$ & 10 \\
\hline null & $7+8$ & $5+10$ & 2 & null & $7+8$ & $2+12$ & 1 \\
\hline null & $7+9$ & $2+12$ & 1 & null & $7+9$ & $2+12$ & 4 \\
\hline
\end{tabular}

In each subspecies, the most frequent combination also differed, and in some cases the most frequent one in one subspecies was the least in another. In club wheat, although there was a great number of combinations, any of them can be considered hegemonic, and the most frequent combination was $2^{*}, 7+8$, and $2+12$, which appeared in 9 of the 55 accessions. This combination was only found in three accessions of macha wheat, but it was absent in Indian dwarf wheat. A similar situation occurred with the most frequent combination in Indian dwarf wheat (null, $17+18$, and $2+12$ ), which was only detected in two accessions of club wheat and one of macha wheat.

The Glu-1 quality score [32] for this last combination was associated with low gluten quality (score $=6$ ), while the first combination $\left(2^{*}, 7+8\right.$, and $\left.2+12\right)$ had a higher value and was associated with medium gluten quality (score $=8$ ). Only one club wheat accession showed the highest score (10 for 1, $7+8$, and $5+10$ ) according to the scale of Payne et al. [32] developed for use in modern breeding programs targeting industrial bread-making processes.

\subsection{Genetic Diversity}

Some genetic parameters measured in each subspecies are shown in Table 3. These parameters detected important genetic erosion both in club wheat and macha wheat. The Ne values were especially 
significant for the Glu-B1 locus in both subspecies, with values lower than $43 \%$ of the allelic variation detected $(A)$. However, the genetic diversity $(\mathrm{He})$ of this locus was high, possibly related to the fact that no hegemonic allele was detected in these subspecies. Nevertheless, the low frequency of most of the alleles suggested that these could easily be missed due to genetic drift effects.

Table 3. Genetic parameters for the Glu-1 loci in the evaluated subspecies.

\begin{tabular}{lcccc}
\hline \multicolumn{1}{c}{ Subspecies } & Locus & $\boldsymbol{A}$ & $\mathrm{Ne}$ & $\boldsymbol{H} \boldsymbol{e}$ \\
\hline \multirow{3}{*}{ Club wheat } & Glu-A1 & 3 & 2.53 & 0.605 \\
& Glu-B1 & 11 & 4.62 & 0.783 \\
& Glu-D1 & 3 & 1.57 & 0.364 \\
\cline { 2 - 5 } Macha wheat & Mean & 5.67 & 2.91 & 0.584 \\
\hline \multirow{5}{*}{ Indian dwarf wheat } & Glu-A1 & 3 & 2.18 & 0.542 \\
& Glu-D1 & 6 & 2.56 & 0.609 \\
& Mean & 4.00 & 2.04 & 0.509 \\
\hline & Glu-A1 & 2 & 1.45 & 0.553 \\
\hline & Glu-D1 & 6 & 3.93 & 0.310 \\
\cline { 2 - 5 } & Mean & 3.00 & 2.13 & 0.352 \\
\hline
\end{tabular}

These differences were slightly lower in Indian dwarf wheat, for which only the Glu-B1 locus showed certain variability. In contrast, the Glu-D1 locus was similar for all accessions evaluated (Glu-D1a allele $=2+12)$.

\section{Discussion}

Since the mid-twentieth century, the development of high-yield wheat cultivars has led to the replacement of local varieties, old varieties, or ancient wheat by modern cultivars [5]. Many of these materials remain stored in gene banks, being used in many cases as resources to generate new cultivars. However, new food movements have led to some of these neglected or underutilized crops beginning to be used as sources in traditional products. Unfortunately, for years, because of the lack of appropriate flours, these 'traditional' products have been made with modern flours that must be conditioned for these uses; consequently, whether these old materials would be better for making these traditional products remains unknown. For this reason, their analysis is necessary to determine the quality traits associated with optimal adaptation for this traditional food. This would permit both their recovery as new crops and the development of modern cultivars with similar quality characteristics but better agronomic traits. In any case, it is important to indicate that these ancient or neglected wheats cannot substitute for modern wheat; both types are clearly complementary within a more varied diet. Among these neglected wheats, the three subspecies evaluated in this study are options to independently explore, and they can be used as sources of agronomic traits. In this respect, Indian dwarf wheat has been evaluated as a potential source of stripe rust resistance [33] and salt tolerance [34]. However, the aspects related to flour quality have been seldom studied, mainly because most studies aimed to obtain new wheat cultivars with strong gluten that could be used for flour enrichment. In this context, these old wheats are not the best candidates. The interest in these wheat types has its origin in the recovery of traditional products performed with old techniques [35]. For this reason, comparisons with modern standards should be made cautiously.

Numerous studies carried out with wide collections of wheat have shown the high variation for HMWGs in this crop [9]. The high level of polymorphisms in these genes is a consequence of their physiological role. During the germination process, the seed storage proteins are a source of amino acid residues in the synthesis of new proteins needed for plant development [36]. Apparently, these proteins 
have no catalytic function, which has meant that changes in their amino acid composition or size has had no effect on plant viability and permits that the mutations can be easily fixed, generating wide polymorphisms. Numerous variants of these proteins have been detected in wheat, although many appear at very low frequencies, which implies a high risk of loss due to genetic drift processes.

However, the relationship of these proteins with food products has resulted in some alleles being fixed and some discarded, as the flour of these genotypes has shown better adaptation to a specific product or use. For this reason, variations are lower in modern than in ancient wheat. Although our knowledge of these proteins and their roles in flour quality is relatively recent [9], it is obvious that some of these alleles were empirically fixed by the farmers and bakers over time. They selected flours adapted to traditional uses, and, consequently, the HMWG combinations that better suited these quality properties were fixed, while the rest were gradually discarded. In this respect, the Indian dwarf wheat evaluated here is a wheat type endemic to the north of India and Pakistan associated with the elaboration of flat breads such as chapati [2], which requires flour with a medium gluten strength (score $=4-6$ ) and high extensibility. Club wheat was also traditionally used to make cookies, for which weak flour is required; now, this wheat has some commercial importance in the Pacific Northwest of the USA because of this use [37].

Many other examples about the preferred use of ancient wheat and old wheat landraces for the elaboration of traditional wheat products are found in the literature. In a recent study in Turkey, Morgounov et al. [38] showed that, in different regions across the country, farmers have access to modern cultivars but still kept growing their landraces. Their main reason to do this is because they were happy with the grain quality and its suitability for homemade products (mainly typical loaves and thin types with bread wheat, and bulgur with durum wheat). In the same study, only $30 \%$ of the farmers rated the yield of the landraces as good, which clearly indicates that, despite their higher yields, modern wheat varieties do not satisfy them because their end-use quality is inadequate. This is in agreement with Bardsley et al. [39], who explained that the landrace Kirik is retained in Northeast Anatolia villages primarily because the baking qualities in the flour are appropriate for the local bread, lavash. Further studies are necessary to determine the grain quality components and properties that led to this preference, something that has already started in that country [40]. In other cases, such as the bread named "Pane Nero di Castelvetrano" from Sicily (Italy), the association between its end-use quality and the use of a specific landrace to elaborate it has been established [41]. Castelvetrano black bread is characterized by the intense brownness of its crumb. This bread is elaborated with durum wheat, and at least $20 \%$ of the flour blend should be from the autochthonous durum cultivar Timilia [42]. In fact, this landrace has high concentration of phenolic compounds that, when coupled with its extremely high polyphenol oxidase (PPO) activity, leads to the intense brownness of crumb [43]. On the other hand, modern durum cultivars are characterized for their low PPO activity, which makes them unsuitable for the preparation of this bread type. Other Italian traditional breads such as "Pane di Altamura" or "Pagnotta del Dittaino" (which have the European mark of Protected Designation of Origin, PDO) need to also be manufactured, by law, with durum semolina or re-milled semolina of specific cultivars (Appulo, Arcangelo, Duilio, and Simeto) to confer these breads their distinctive sensory properties and longer shelf-life [42,44]. These cultivars were developed in different times of the twentieth century, but they all have in their pedigree Cappelli, an old Italian cultivar derived from the Tunisian landrace Jennah Khetifa [45].

Although the variation for seed storage proteins of these subspecies was previously evaluated by Rayfuse and Jones [24] and $\mathrm{Xu}$ et al. [25], notable differences between our data and these previous findings were found. The detection of alleles that they did not find, together with changes in the frequencies of numerous common alleles, were especially significant. One possible cause of these differences is the use of different polyacrylamide concentrations in separation gels. Some of these subunits (e.g., subunit $2^{*}$ vs. subunit 2 ) are difficult to detect in SDS-PAGE gel with $10 \%$ polyacrylamide concentration (C: $2.67 \%$ ). For this reason, in the current study, the subunits were separated in SDS-PAGE gels using different concentrations (T: $8 \%, \mathrm{C}: 1.28 \%$ ) that our previous studies had confirmed as more 
adequate for separation of these proteins [17-19]. In total, 3 alleles were found for Glu-A1, 15 for Glu-B1 (4 of them novel), and 3 for Glu-D1.

Probably because of their endemic condition and local use, the observed variation was especially low in macha and Indian dwarf wheat. This high homogeneity is very notable in all materials that have been cyclically used and neglected, as the narrowing of the genetic base, and subsequent reduced selection pressure, results in the loss of spontaneous variants and fixing of the most common ones by genetic drift. Compared with other hexaploid wheat subspecies, such as spelt, the variation was similar for the Glu-A1 and Glu-B1 loci, whereas variation for the Glu-D1 locus detected here was slightly lower than that found in a wide collection of this hulled wheat of Spanish origin, where up to nine alleles were detected for this locus [19]. This could be a consequence of the wider geographical area where it is grown and its more diverse uses [46].

\section{Conclusions}

The neglected/underutilized wheat subspecies evaluated here showed wide polymorphisms for HMWGs, including novel alleles not previously described. Although the effects of these new allelic variants on technological properties should be further evaluated, this information may be of interest to wheat breeders for choosing parents to obtain recombinant lines with different gluten properties. Nevertheless, in the context of healthier and sustainable food, and as sources of genes for quality improvement in common wheat, these subspecies could be used to develop new/old crops with good agronomic traits and optimal flour characteristics for new and traditional products.

Supplementary Materials: The following are available online at http://www.mdpi.com/2073-4395/9/11/755/s1, Table S1: Allelic composition for the Glu-1 loci in club wheat, Table S2: Allelic composition for the Glu-1 loci in macha wheat, Table S3: Allelic composition for the Glu-1 loci in Indian dwarf wheat.

Author Contributions: J.B.A. conceived and designed the study. J.B.A. and C.G. performed the experiments, analyzed the data, and wrote the paper. Both authors read and approved the final manuscript.

Funding: This research was supported by grant RTI2018-093367-B-I00 from the Spanish State Research Agency (Ministry of Science, Innovation and Universities), co-financed by the European Regional Development Fund (FEDER) from the European Union. Carlos Guzman gratefully acknowledges the European Social Fund and the Spanish State Research Agency (Ministry of Science, Innovation and Universities) for financial funding through the Ramon y Cajal Program (RYC-2017-21891).

Acknowledgments: We thank the National Small Grain Collection (Aberdeen, USA) for supplying the analyzed material.

Conflicts of Interest: The authors declare no conflicts of interest.

\section{References}

1. Harlan, J.R. The early history of wheat: Earliest traces to the sack of Rome. In Wheat Science-Today and Tomorrow; Evans, L.T., Peacock, W.J., Eds.; Cambridge University Press: Cambridge, UK, 1981; pp. 1-29.

2. Faridi, H.; Faubion, J.M. Wheat End-Uses Around the World; American Association of Cereal Chemists: St. Paul, MN, USA, 1995.

3. Matz, S.L. Bakery Technology and Engineering; Avi Publishing Co.: Westport, CT, USA, 1960.

4. Trichopoulou, A.; Soukara, S.; Vasilopoulou, E. Traditional foods: A science and society perspective. Trends Food Sci. Technol. 2007, 18, 420-427. [CrossRef]

5. Esquinas-Alcazar, J. Protecting crop genetic diversity for food security: Political, ethical and technical challenges. Nat. Rev. Genet. 2005, 6, 946-953. [CrossRef] [PubMed]

6. Jauhar, P.P. Alien Gene Transfer and Genetic Enrichment of Bread Wheat. In Biodiversity and Wheat Improvement, 1st ed.; Damania, A.B., Ed.; ICARDA-A Wiley Sayce Publication: Aleppo, Syria, 1993; pp. 103-119.

7. Alvarez, J.B.; Guzmán, C. Interspecific and intergeneric hybridization as a source of variation for wheat grain quality improvement. Theor. Appl. Genet. 2018, 131, 225-251. [PubMed]

8. Zamir, D. Improving plant breeding with exotic genetic libraries. Nat. Rev. Genet. 2001, 2, 983-989. [CrossRef]

9. Wrigley, C.; Békés, F.; Bushuk, W. (Eds.) Gliadin and Glutenin: The Unique Balance of Wheat Quality; AACC International Press: St. Paul, MN, USA, 2006. 
10. Guzmán, C.; Alvarez, J.B. Wheat waxy proteins: Polymorphism, molecular characterization and effects on starch properties. Theor. Appl. Genet. 2016, 129, 1-16. [CrossRef]

11. Morris, C.F. Puroindolines: The molecular genetic basis of wheat grain hardness. Plant Mol. Biol. 2002, 48, 633-647. [CrossRef]

12. Payne, P.I. Genetics of wheat storage proteins and the effects of allelic variation on bread-making quality. Annu. Rev. Plant Physiol. 1987, 38, 141-153. [CrossRef]

13. Singh, N.K.; Shepherd, K.W. Linkage mapping of genes controlling endosperm storage proteins in wheat. 1. Genes on the short arms of group 1 chromosomes. Theor. Appl. Genet. 1988, 75, 628-641. [CrossRef]

14. Pogna, N.E.; Autran, J.C.; Mellini, F.; Lafiandra, D.; Feillet, P. Chromosome 1B-encoded gliadins and glutenin subunits in durum wheat: Genetics and relationship to gluten strength. J. Cereal Sci. 1990, 11, 15-34. [CrossRef]

15. Metakovsky, E.V.; Novoselskaya, A.Y.; Kopus, M.M.; Sobko, T.A.; Sozinov, A.A. Blocks of gliadin components in winter wheat detected by one-dimensional polyacrylamide gel electrophoresis. Theor. Appl. Genet. 1984, 67, 559-568. [CrossRef]

16. Harberd, N.P.; Bartels, D.; Thompson, R.D. DNA restriction-fragment variation in the gene family encoding high molecular weight (HMW) glutenin subunits of wheat. Biochem. Genet. 1986, 24, 579-596. [CrossRef] [PubMed]

17. Caballero, L.; Peña, R.J.; Martín, L.M.; Alvarez, J.B. Characterization of Mexican Creole wheat landraces in relation to morphological characteristics and HMW glutenin subunit composition. Genet. Resour. Crop Evol. 2010, 57, 657-665. [CrossRef]

18. Ayala, M.; Guzmán, C.; Peña, R.J.; Alvarez, J.B. Diversity of phenotypic (plant and grain morphological) and genotypic (glutenin alleles in Glu-1 and Glu-3 loci) traits of wheat landraces (Triticum aestivum) from Andalusia (Southern Spain). Genet. Resour. Crop Evol. 2016, 63, 465-475. [CrossRef]

19. Caballero, L.; Martin, L.M.; Alvarez, J.B. Allelic variation of the HMW glutenin subunits in Spanish accessions of spelt wheat (Triticum aestivum ssp spelta L. em. Thell.). Theor. Appl. Genet. 2001, 103, 124-128. [CrossRef]

20. Caballero, L.; Martín, L.M.; Alvarez, J.B. Variation and genetic diversity for gliadins in Spanish spelt wheat accessions. Genet. Resour. Crop Evol. 2004, 51, 679-686. [CrossRef]

21. Caballero, L.; Martín, L.M.; Alvarez, J.B. Agrobiodiversity of hulled wheats in Asturias (North of Spain). Genet. Resour. Crop Evol. 2007, 54, 267-277. [CrossRef]

22. Caballero, L.; Martín, L.M.; Alvarez, J.B. Genetic diversity in Spanish populations of Triticum spelta L. (escanda): Example of an endangered genetic resource. Genet. Resour. Crop Evol. 2008, 55, 675-682. [CrossRef]

23. Ayala, M.; Alvarez, J.B.; Yamamori, M.; Guzmán, C. Molecular characterization of waxy alleles in three subspecies of hexaploid wheat and identification of two novel Wx-B1 alleles. Theor. Appl. Genet. 2015, 128, 2427-2435. [CrossRef]

24. Rayfuse, L.M.; Jones, S.S. Variation at Glu-1 loci in club wheats. Plant Breed. 1993, 111, 89-98. [CrossRef]

25. Xu, L.-L.; Li, W.; Wei, Y.-M.; Zheng, Y.-L. Genetic diversity of HMW glutenin subunits in diploid, tetraploid and hexaploid Triticum species. Genet. Resour. Crop Evol. 2009, 56, 377-391. [CrossRef]

26. Payne, P.I.; Lawrence, G.J. Catalogue of alleles for the complex gene loci, Glu-A1, Glu-B1 and Glu-D1 which code for high-molecular-weight subunits of glutenin in hexaploid wheat. Cereal Res. Commun. 1983, 11, 29-35.

27. Laemmli, U.K. Cleavage of structural proteins during the assembly of the head of bacteriophage T4. Nature 1970, 227, 680-685. [CrossRef]

28. Marshall, D.; Brown, A. Optimum Sampling Strategies in Genetic Conservation. In Crop Genetic Resources for Today and Tomorrow; Frankel, O.H., Hawkes, J.G., Eds.; Cambridge University Press: Cambridge, UK, 1975; pp. 53-70.

29. Nei, M. Genetic distance between populations. Am. Nat. 1972, 106, 283-292. [CrossRef]

30. Nei, M. Analysis of gene diversity in subdivided populations. Proc. Natl. Acad. Sci. USA 1973, 70, 3321-3323. [CrossRef]

31. McIntosh, R.A.; Yamazaki, Y.; Dubcovsky, J.; Rogers, W.J.; Morris, G.; Appels, R.; Xia, X.C. Catalogue of Gene Symbols for Wheat. 2013. Available online: http://www.shigen.nig.ac.jp/wheat/komugi/genes/macgene/2013/ GeneSymbol.pdf (accessed on 23 August 2019).

32. Payne, P.I.; Nightingale, M.A.; Krattiger, A.F.; Holt, L.M. The relationships between HMW glutenin subunit composition and the bread-making quality of British-grown wheat varieties. J. Sci. Food Agric. 1987, 40, 51-65. [CrossRef] 
33. Badridze, G.; Weidner, A.; Asch, F.; Börner, A. Variation in salt tolerance within a Georgian wheat germplasm collection. Genet. Resour. Crop Evol. 2009, 56, 1125-1130. [CrossRef]

34. Chen, S.-S.; Chen, G.-Y.; Chen, H.; Wei, Y.-M.; Li, W.; Liu, Y.-X.; Liu, D.-C.; Lan, X.-J.; Zheng, Y.-L. Mapping stripe rust resistance gene $\mathrm{Y} r \mathrm{Sph}$ derived from Triticum sphaerococcum Perc. with SSR, SRAP, and TRAP markers. Euphytica 2012, 185, 19-26. [CrossRef]

35. Miedaner, T.; Longin, F. Neglected Cereals: From Ancient Grains to Superfood; Agrimedia: Clenze, Germany, 2016.

36. Shutov, A.D.; Vaintraub, I.A. Degradation of storage proteins in germinating seeds. Phytochemistry 1987, 26, 1557-1566. [CrossRef]

37. Peterson, C.J.; Allan, R.E.; Peterson, C.L.J. US Pacific Northwest Region. In The World Wheat Book: A History of Wheat Breeding; Bonjean, A.P., Angus, W.J., Eds.; Lavoisier Publishing Inc.: Paris, France, 2001; pp. 407-429.

38. Morgounov, A.; Keser, M.; Kan, M.; Küçükçongar, M.; Özdemir, F.; Gummadov, N.; Muminjanov, H.; Zuev, E.; Qualset, C.O. Wheat landraces currently grown in Turkey: Distribution, diversity, and use. Crop Sci. 2016, 56, 3112-3124. [CrossRef]

39. Bardsley, D.; Thomas, I. Valuing local wheat landraces for agrobiodiversity conservation in Northeast Turkey. Agric. Ecosyst. Environ. 2005, 106, 407-412. [CrossRef]

40. Akcura, M.; Kokten, K.; Akcacik, A.G.; Aydogan, S. Pattern analysis of Turkish bread wheat landraces and cultivars for grain and flour quality. Turk. J. Field Crops 2016, 21, 120-130. [CrossRef]

41. Giancaspro, A.; Colasuonno, P.; Zito, D.; Blanco, A.; Pasqualone, A.; Gadaleta, A. Varietal traceability of bread 'Pane Nero di Castelvetrano' by denaturing high pressure liquid chromatography analysis of single nucleotide polymorphisms. Food Control 2016, 59, 809-817. [CrossRef]

42. Pasqualone, A. Italian Durum Wheat Breads. In Bread Consumption and Health; Pedrosa Silva Clerici, M.T., Ed.; Nova Science Publishers: New York, NY, USA, 2012; pp. 57-79.

43. Taranto, F.; Delvecchio, L.N.; Mangini, G.; Del Faro, L.; Blanco, A.; Pasqualone, A. Molecular and physico-chemical evaluation of enzymatic browning of whole meal and dough in a collection of tetraploid wheats. J. Cereal Sci. 2012, 55, 405-414. [CrossRef]

44. Pasqualone, A.; Alba, V.; Mangini, G.; Blanco, A.; Montemurro, C. Durum wheat cultivar traceability in PDO Altamura bread by analysis of DNA microsatellites. Eur. Food Res. Technol. 2010, 230, 723-729. [CrossRef]

45. Maccaferri, M.; Sanguineti, M.C.; Donini, P.; Porcedu, E.; Tuberosa, R. A Retrospective Analysis of Genetic Diversity in Durum Wheat Elite Germplasm Based on Microsatellite Analysis: A Case Study. In Durum Wheat Breeding: Current Approaches and Future Strategies; Royo, C., Nachit, M.N., Di Fonzo, N., Araus, J.L., Pfeiffer, W.H., Slafer, G.A., Eds.; Haworth Press: New York, NY, USA, 2005; pp. 99-142.

46. Peña-Chocarro, L. Promoting the Conservation and Use of Underutilized and Neglected Crops. In Situ Conservation of Hulled Wheat Species: The Case of Spain, Hulled Wheats; Padulosi, S., Hammer, K., Heller, J., Eds.; International Plant Genetic Resources Institute: Rome, Italy, 1996; pp. 129-146. 